\title{
Social and economic characteristics of AIDS patient in Jordan: A descriptive field study
}

\author{
Hussein Omar Al-Khozahe \\ Prof. Dr. Dept of Applied Sociology \\ College of Princess Alia University \\ Al-Balqa Applied University, Jordan
}

\begin{abstract}
This study aims to identify the status of AIDS patients in Jordan and their social and economic characteristics through detecting number of the cases and ways of contracting this disease. The patients were classified according to age, gender, place of contracting the disease, and their origin. The study came with the following results: The total number of the detected cases since the establishment of the national AIDS program for disease prevention in 1986 till the end of 2015 was 1222 cases; 325 Jordanian and 897 foreigners. The total number of deaths of this disease was 115. Having illegitimate sex contact is the first reason for AIDS infection( $55 \%$ ); most of these cases were outside Jordan. the age categories (30-39) and (40-49) came first among AIDS patient (52\%).Additionally, $20 \%$ of the AIDS patients were female and $\mathbf{2 6 . 6 \%}$ of the total number of AIDS patients were Jordanians. The moment the disease is discovered, the AIDS patient feels shocked, denial and regret then he starts accepting it and integrating into society.
\end{abstract}

Key words: Aids, Counseling and Awareness Center, Victims of Aids, Social Workers

\section{INTRODUCTION}

AIDS disease is considered one of the most sexually transmitted diseases and it is a source of threat to human beings. It is a global epidemic which has no cure $100 \%$ (Lori,2000).furthermore, this disease is one of the most horrible health crises for its effects on human as social and psychological shock, loss of control over emotions and feelings, denial, fear of disease , loss of self-esteem,..etc(The Jordan Red Crescent ,2007). The AIDS disease has direct social effect in the society; it causes health problems in addition to social ones as family and relatives relations get weak which makes the patients feel isolated (Ahmad,1990). Even the infected children may be exposed to negative reactions from the society as rejecting them and refusing to accept them in the schools to continue their learning . At the moment of discovering the disease, the AIDS Patients felt shocked, denial, blame and pangs of remorse but later he starts to accept the disease and integrate with the society.

\section{PROBLEM OF THE STUDY}

The problem is represented by the social and psychological pressures facing the AIDS patients and make them feel embarrassed for asking for treatment and advice by visiting the centers of awareness and education of AIDS especially if they feel that their privacy has been violated and the society reject them. Therefore, the AIDS patients prefer to live in isolation before and after their sickness is revealed and consequently the number of AIDS patients who visited awareness and guidance centers does not exceed (40\%) while those who did not visit the centers, their number is still unknown . 


\section{SIGNIFICANCE OF THE STUDY}

The social ,demographic and economic effects of AIDS are horrible. In some societies, AIDS disease kills a big number of young people which will lead one day to have a generation lacks adult category( 20-30). Because AIDS disease infects the adult, its effect is seen clearly in the sectors of army, education, agriculture, industry, transport and economy in general(World Bank,2003).additionally, experts and specialized in the economy depression pointed to the horrible and disastrous results of this fatal disease and unless anything is done, there will be total economy depression within three generations in the countries that suffer greatly because of this disease(Khozai,2004).

The spread of silence culture in the Islamic and Arab countries that obliged the woman to be obedient and no to ask her husband about his sexual relations which makes her more exposed to have an infection . the woman has to ignore the man's multi sexual relations with more than a woman. It should be stated here that $90 \%$ of AIDS cases at Saudi Arabia was because of illegitimate sexual relations(Ra'i newspaper,2003).In Sudan which has the highest proportion of Aids cases in middle east and north of America was also because of the illegitimate sexual relations with 97\% (Al-Dastour,2006) while in Lebanon the proportion of AIDS cases for the some reason was 79\% including the Homosexual relations with 23\%. In Egypt, the official records showed that the main reason for AIDS infection was either insecure sex between men and women with $50 \%$ or homosexuality amng men with $20 \%$.

\section{AIDS disease in the World}

This disease was first discovered in USA and UK among who make homosexual or bisexual relations and about $71 \%$ of AIDS patients were infected sexually. The World Health Organization assured that the women's vulnerability to infection is higher than the man and there are 250 million cases infected sexually yearly (Mahmoud,2001). After 36 years of recording the first AIDS case in USA in 1981(Kamal,1992) till the 2015, the number of AIDS patients is estimated by 35 million, most of them (25 million) are from developed countries and it is expected that there will be yearly about 116000 new cases (WHO,2015). The latest report concerning AIDS showed that 168 countries informed WHO of having AIDS cases in their countries (Graeme stewart,2005) while in 1986 there were 29000 cases in71 countries (Sahawna,1988).

\section{AIDS disease in Jordan}

The Jordanian society with its special characteristics where values ,habits, traditions are greatly respected imposes behaviors to be followed by every member in the society(Khozai,2003). Furthermore, the Jordanian society is committed to the holy books that forbids adultery which is one of the ethic crimes(Abd tawab,1986),or illegitimate sexual contact with others for their horrible effects as diseases, social problems and family loss(Ateia,2003).

Article (282) of the Jordanian Punishment Law states: the Adulterous female and her partner are punished by prison form 6 months till 2 years(Najm,1994). According to Punishment Law, adultery is defined by sexual contact between a married woman or am $\mathrm{n}$ with other than his wife or her husband(Hosni,1978).

Despite of these regulations, laws, habits , traditions and religion that forbid adultery but the Jordanian statistics in this field revealed that $55 \%$ of the cases was because of illegitimate sexual relations (Ministry of Health,2015). 
The Jordanian Ministry of Health pays much attention to the AIDS disease through the effective effort in the field of prevention and health care. And the ministry considers the voluntary testing and counseling services a very important point to other activities of prevention of this disease and support to the patients and therefore, these services will be helpful to the individuals and couples.

The first AIDS case was recorded for a Jordanian woman in 1986 and it was because of a blood transfer abroad (Belad Newspaper,2002). Since that date, the Jordanian program for AIDS prevention was adopted and the Ministry of Health adopted the main goals of the international AIDS program which fighting the disease, reduce its spread and its effect on the patient and his family and the society in general. the total number of the diseases which were discovered from 1986 (the date of establishing the national program for AIDS prevention) till 2015 was 1222including 325 Jordanian cases and 897 cases for non Jordanians . the total number of deaths because of this disease was 115( Ministry of Health,2015).

In 1999, Ministry of Health established Voluntary Counseling and Testing (VCT) Centre to provide advice and help to the youth to enable them to make their own decisions towards behaviors that may cause health problem as AIDS. Moreover, the center provide counseling and social, psychological and health care to the AIDS patients and their families in addition to supply them with bulletins, regulations and guidance concerning prevention of this disease(Ministry of Healt,1999). The hotline in this center is being supervised by three employees: health supervisor, a doctor, social expert).

\section{TERMS DEFINITIONS}

1. AIDS: it is one of the sexually transmitted diseases in the world which has no treatment till now . It transmits form the man to the woman and vice versa or form a man to a man by polluted injections, multi sexual and illegal relations and having some other venereal disease.

2. Coexistence with AIDS: accepting the disease, following up the treatment, and the specialized instructions.

3. Coexistence with society: integration into the society and living with respect and nondiscrimination .

4. AIDS patient : the patient who was proved to have this disease and visited the medical center for help.

5. Difficulties : it is the problem facing the patients that cannot be solv

\section{GOALS OF THE STUDY}

1. To identify the social and economic characteristics of AIDS patients in Jordan according to the place of infection, age, gender, and way of infection).

2. To determine the difficulties facing AIDS patients in Jordan.

\section{Population of the study}

\section{METHODOLOGY OF THE STUDY}

The study used the comprehensive social survey for all AIDS patients in Jordan who visited the counseling centers in different Jordanian districts (Amman, Zarqa , Jerash , Madaba , Aqaba, AlBalqa).

The study's instrument \& its reliability and validity 
For collecting data, the researcher used a questionnaire consisted of 30 items distributed into dimensions: the first one related to the patients' general information while the other addresses the difficulties facing the patients in Jordan and the suggestions they have to face these difficulties. To check the instrument's validity, it was presented to five arbitrators who are specialized in (medicine ,sociology, social service, psychology, religion) to identify its appropriateness to the study's goal and their notes were taken into account. The instrument's reliability was checked by applying it on a sample consisted of 10 patients and Alpha coefficient was calculated and its value was (0.89\%) which indicated that the instrument has a high degree of reliability.

\section{Statically treatment}

The descriptive method was used to analyze data and the means and standard deviations were used. The results were as follows:

Results concerning the first goal: identifying the AIDS patients' social and economic characteristics in Jordan according to ( place of infection, age, gender, way of infection).

Although most of the cases took place outside Jordan(67.7\%) as it is illustrated in table(1), about 95 cases were in Jordan which indicated local infection to the cause of the disease and therefore there is a need to condense health awareness, guidance and prevention programs to reduce the spread of this disease.

Table(1) showed that the categories(20-29) and (30-39) are the highest one in being infected by this disease with (35.6\%) each, followed by the category(40-49) with $(14.9 \%)$. It is noted that the age of $76 \%$ of the patients was less than 40 years and it is the period of being active economically and sexually. Data showed that $61 \%$ of the patients were males while $39 \%$ were females.

The previous table also showed the $55 \%$ of the patients had the infection through illegitimate sexual contact, blood transmission was the cause of $20.3 \%$, Homosexuality practices (11.6\%), drugs and intravenous injection(2.2\%) whereas the infection from the mother to her child was $(2.8 \%)$. And thus, much attention should be given to awareness programs , education sessions focusing on the religious aspect in this issue. In the same context, Sheikh Mohammad Sayed Tantawi ,sheikh of Al-Azhar, called all the religious leaders in their societies to fight against AIDS to protect the young who will be the leaders in the future(Tantawi,2006).

Although most of the infection cases occurred among non-Jordanians with (73.4\%) as it is illustrated in table (1), about (26.6\%) of the infection cases was among the Jordanian which indicates local transmission to the disease and therefore there is an eager need to have more education and awareness, and prevention programs to reduce the spread of this disease locally. 
Table (1):Distribution of AIDS patients among the Jordanian according to place of infection (1986-2015)

\begin{tabular}{|c|c|c|c|c|}
\hline Place & Male & Female & Total & Proportion \\
\hline Inside Jordan & 64 & 31 & 95 & $\% 29.2$ \\
\hline Outside Jordan & 193 & 24 & 217 & 67.7 \\
\hline Unknown & 12 & 1 & 13 & 4.1 \\
\hline Total & 269 & 56 & 325 & 100 \\
\hline Age category & Male & Female & Total & Proportion \\
\hline Less than 4 & 7 & 4 & 11 & 0.9 \\
\hline $14-5$ & 18 & 2 & 20 & 1.6 \\
\hline $19-15$ & 8 & 5 & 13 & 1.0 \\
\hline $29-20$ & 245 & 203 & 445 & 35.6 \\
\hline $39-30$ & 259 & 188 & 447 & 35.6 \\
\hline $49-40$ & 138 & 49 & 187 & 14.9 \\
\hline More than 50 & 89 & 28 & 117 & 9.3 \\
\hline Unknown & 11 & 3 & 14 & 1.1 \\
\hline Total & $\begin{array}{l}775 \\
\% 61 \\
\end{array}$ & $\begin{array}{l}482 \\
\% 39 \\
\end{array}$ & $\begin{array}{l}1257 \\
\% 100 \\
\end{array}$ & $\% 100$ \\
\hline Way of infection & Male & Female & Total & Proportion \\
\hline Sexual relations & 139 & 37 & 176 & $\% 55$ \\
\hline Blood transmission & 47 & 18 & 65 & 20.3 \\
\hline Homosexuality & 37 & & 37 & 11.6 \\
\hline Drugs addiction & 5 & 2 & 7 & 2.2 \\
\hline Mother to her child & 6 & 3 & 9 & 2.8 \\
\hline Unknown & 21 & 5 & 26 & 8.1 \\
\hline Total & 255 & 65 & 320 & 100 \\
\hline Place of infection & Male & Female & Total & Proportion \\
\hline Jordanian & 266 & 59 & 325 & 26.6 \\
\hline Non Jordanians & 509 & 388 & 897 & 73.4 \\
\hline Total & 775 & 477 & 1222 & $\% 100$ \\
\hline
\end{tabular}

Results of the second goal : identifying the difficulties facing AIDS patients in Jordan.

Table (2):Difficulties facing AIDS patients arranged ascending according to the means of the difficulties

\begin{tabular}{|l|c|c|c|c|}
\hline \multicolumn{1}{|c|}{ Difficulty } & M & Std & Rank & Degree \\
\hline $\begin{array}{l}\text { Shame, discrimination and sensitivity to the risk } \\
\text { of the disease. }\end{array}$ & 3.78 & 0.45 & 1 & High \\
\hline Lack of privacy y in hospitals ( public \& private). & 3.75 & 0.43 & 2 & High \\
\hline Adjusting dangerous behaviors & 3.69 & 0.41 & 3 & High \\
\hline Financial problems( low income) & 3.61 & 0.35 & 5 & moderate \\
\hline Transport & 3.57 & 0.41 & 6 & Moderate \\
\hline
\end{tabular}

Table (2) showed the difficulties facing AIDS patients ordered ascending according to the their means. The difficulty of shame and discrimination because of the disease sensitivity came first with high degree, followed respectively by the difficulty of lack of privacy specially in the public and private hospitals with high degree, the difficulty of adjusting dangerous behaviors with high degree, the patients' with financial problems with moderate degree and means of transport with moderate degree.

\section{RECOMMENDATIONS}

1. Educate the patients and aware them of shame and discrimination of the disease risk and sensitivity and accepting the disease. 
2. Prepare programs and education strategies for the category that is mainly exposed to this disease in the society (young, drivers, prisoners, refugees) to aware them of the horrible disease, ways of infection and prevention.

3. Follow all the medical and administrative procedures to provide privacy and confidentiality ( public and private hospitals).

4. Work on establishing a Fund supported by the private and public sectors to help the patients who are financially incapable to secure life necessities.

\section{References:}

World Bank(2003). AIDS leads to economic explosion, a report to World Bank experts in the annual meeting,Dubai,UAE,Al-Ra`I newspaper,12058,p 55.

the Jordanian Red Crescent (2007). Immunity deficiency Virus \&AIDS, the Jordanian Red Crescent publications, Jordan, Amman.

Anwar Ateia.(2003). Women ethic crimes in the Jordanian society: field study, Unpublished thesis,Jordan,Amman,p55.

Hussein Khozai.(2003). AIDS in Jordan, article published in Al-Rai news paper 11949,p55.

Hussein Khozai.(2004).sexual education, silence \&shame, published report in Al-Arab Al-yum,V2,p8.

Albilad newspaper.(2002). A report on AIDS disease in Jordan,V441.

AL-Dastour newspaper (2006). A report on AIDS disease, V14133.

Al-Ra`I newspaper(2003). A report on AIDS, Riyadh, V 12223.

Jamal,M.(2001). Muslim woman in the era of globalization, Egyptian Dar Kitab, p44.

Refa't, Kamal(1992). The whole of AIDS, Dar Akhbar Alyuim, Cairo,p15.

Fawzi,Sahawnah.(1988).Aids is a crisis in public Health, AL-resala Institution, Beirut, Lebanon, p15.

Seid, Ahmad.(1990). An introduction in the public health \&society medicine,Cairo,p19.

Mohammad,S,Tantawi.(2006). A speech to Al-Azhar Sheikh in the second regional forum for religious leaders to fight AIDS in the Arab countries, Cairo.

Mohamad,S, Najm .(1994). Crimes against persons ,Dar thagafa,Amman,Jordan,pp274-280.

Mahmoud,N,H.(1978).Punishment Law( fifth section),Dar al-nahda al-arabia,Cairo,p 456.

Mowad,A.(1986). Comprehensive cyclopedia in the indecent assault crimes, Dar Matboat Jameia,Cairo,p104.

World health organization.(2015).international program of AIDS, regional office of the eastern Mediterranean, Alexandria.

Ministry of Health in Jordan.(1997).evaluating health services, Unpublished third report,Amman,Jordan,p 144.

Ministry of Health in Jordan.(2015). Special report of counseling \& awareness center, Ministry of Health,Amman,Jordan.

http://ar.islamway.net/article/43322.2012.)

graeme stewart.(2003)., Man aging HIV , first published, Australasian medical publishing company limited ( ACN $00005854) 2003$.p 73.

Lori Ashford . $(2000)$. New perspectives on population : lessons from Cairo population Bulletin 50 , no 1, P 10 . Accessed online at: ( www. Gateway.ovid.com)

http://www.jbcnews.net/mobile/article/141914-64- D8\%A5\%D8\%B5\%D8\%A7\%D8\%A8\%D8\%A9-

\%D8\%A8\%D8\%A7\%D9\%84\%D8\%A7\%D9\%8A\%D8\%AF\%D8\%B2-\%D9\%81\%D9\%8A-

\%D8\%A7\%D9\%84\%D8\%A7\%D8\%B1\%D8\%AF\%D9\%86-\%D9\%81\%D9\%8A-2015 